\title{
Prevalence of Elongated Posterior Talar Process (Stieda Process) Detected by Radiography
}

\author{
Prevalencia del Proceso Talar Posterior Alargado \\ (Proceso de Stieda) Detectado por Radiografía
}

Esin Derin Cicek ${ }^{1}$ \& Müjdat Bankaoglu

CICEK, E. D. \& BANKAOGLU, M. Prevalence of elongated posterior talar process (Stieda process) detected by radiography. Int. J. Morphol., 38(4):894-898, 2020.

SUMMARY: The Stieda process (SP) and os trigonum (OT) are primary risk factors for posterior ankle impingement syndrome. The aim of this study was to elucidate the prevalence of the elongated lateral tubercle of the posterior talar process (SP) and OT in Turkish subjects using lateral ankle radiographs. In this study, 1088 ankle radiographs in the lateral view were evaluated retrospectively using a picture archiving and communication system at two large medical centers. Subjects with a history of mild-to-moderate trauma were selected from the emergency departments of both hospitals from January to June 2019. Data on the presence of SP and OT, the side of the foot that was evaluated, sex, and age were recorded. The prevalence of SP and OT was $16.7 \%$ and $9.3 \%$, respectively, in the Turkish population. The prevalence of SP was significantly higher in men $(20.3 \%)$ than in women $(12.7 \%)(\mathrm{p}=0.001)$. The prevalence of OT was also significantly higher in men $(13.7 \%)$ than in women $(4.3 \%)(\mathrm{p}=0.000)$. The SP and OT were found in $17 \%$ and $9.9 \%$ of the right feet, respectively, and $16.4 \%$ and $8.6 \%$ of the left feet, respectively, with no statistical difference. Approximately one-fourth of the Turkish population had SP or OT, which made them susceptible to posterior ankle impingement syndrome. The prevalence of SP was higher than that of OT, and both were more common in men than in women.

KEY WORDS: Stieda process; Os trigonum; Lateral radiography; Ankle; Turkish population.

\section{INTRODUCTION}

The Stieda process (SP) is an elongation of the posterolateral talar process. It was first described in 1869 (Stieda, 1869), and Barbedelen was the first author to use the term "os trigonum" (OT) in 1885. OT is an accessory ossicle formed by the non-fusion of the secondary ossification center of the talus with the rest of the talus. The formation of OT begins at 11-13 years in boys and 8-10 years in girls. OT is located lateral to the osseous groove of the tendon of the flexor hallucis longus muscle in the posterior process of the talus (Nault et al., 2014). OT or SP may be impinged between the calcaneus and the posterior edge of the tibia, causing the posterior ankle impingement syndrome (PAIS) (Bureau et al., 2000; Robinson \& White, 2002).

Chronic ankle pain has broad differential diagnosis (Robinson \& White). PAIS is a common cause of chronic hindfoot pain, especially in athletes and ballet dancers who perform excessive repetitive plantar flexion of the ankle (Bureau et al.; Niek van Dijk, 2006). Both SP and OT are primary risk factors for PAIS; therefore, their detection is important.

Some studies investigated the incidence of accessory bones in the foot, including OT, in some countries including Turkey, and found a wide variation. However, the prevalence of SP has not been studied in the Turkish population. We aimed to elucidate the prevalence of SP and OT in the Turkish population using lateral ankle radiographs.

\section{MATERIAL AND METHOD}

A double-centered study was performed retrospectively to determine the prevalence of SP and OT. Approval was obtained from the Institutional Review Board for the study at two centers (17073117-050.06, 2019/8). Both centers are training and research hospitals affiliated to the University of Health Sciences.

\footnotetext{
${ }^{1}$ Department of Radiology, Fatih Sultan Mehmet Training and Research Hospital, Istanbul, Turkey.

${ }^{2}$ Department of Radiology, Sisli Hamidiye Etfal Training and Research Hospital, Istanbul, Turkey.
} 
Ankle radiographs in the lateral view of patients with a history of mild-to-moderate trauma were selected from the emergency departments of two hospitals from January to June 2019. Digital Radiography examinations were performed on NS-5000 (SG HealthCare, Korea, 2013) and Axiom Aristos (Siemens, Germany, 2015) devices. The images were evaluated using a picture archiving and communication system (PACS) by two senior radiologists, who had over 10 years of experience in musculoskeletal imaging.

The neutral lateral view was ideal to detect variations in the posterior region of the ankle. It demonstrates true lateral projection of the lower portion of tibia and fibula, ankle joint, and tarsals. Radiographs with poor technique or incorrect positions were not evaluated. Patients with ankle fracture due to current trauma were not included. Patients with severe arthrosis or rheumatic diseases in the hindfoot were excluded. In addition, patients with sequelae of old fracture or those who had undergone surgery in this region were also excluded. Since secondary ossification centers of the talus appear generally at the age of 7-13 years and fuse in one year, children under 15 years of age were excluded from the study. As a result, this study was conducted on 1088 ankle radiographs in the lateral view.

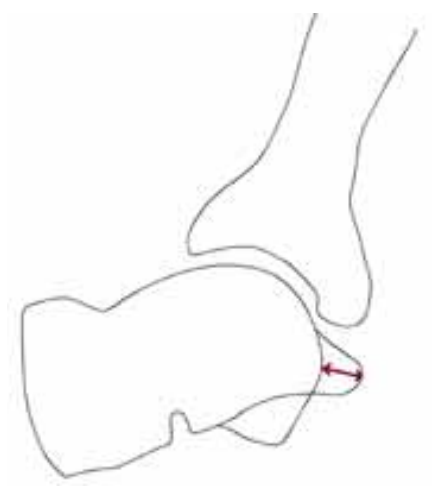

Fig. 1. A schematic illustration of the measurement of the length of the posterolateral process (double-headed arrow).

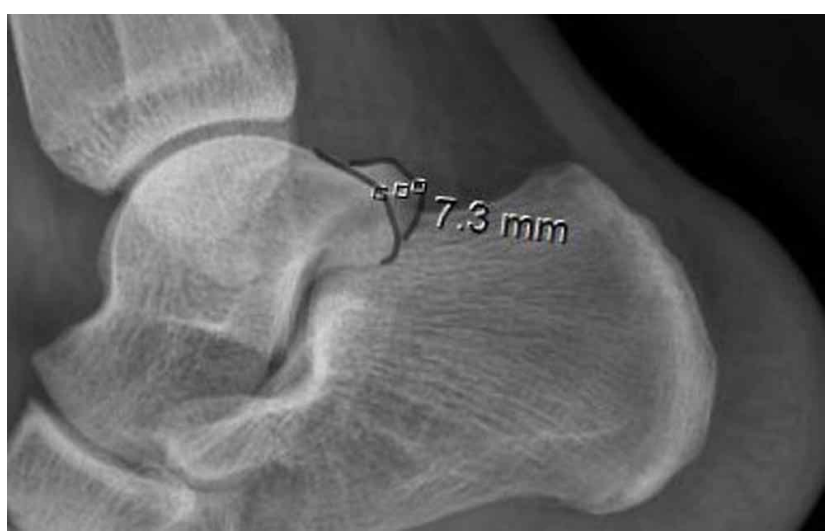

Fig. 2. Lateral radiographs of the ankle showing a prominent posterolateral talar process $(7.3 \mathrm{~mm})$.
In the lateral view, $\mathrm{SP}$ was characterized by the length of the lateral tubercle of the posterior process exceeding the length of the medial tubercle of the posterior process by more than $5 \mathrm{~mm}$. Figure 1 schematizes SP on radiographs. For measurements, the line connecting the most protruding points in the posterior process was used (Figs. 2 and 3). OT was characterized by a bony structure with rounded edges, completely surrounded by the cortex and located adjacent to the posterior process of the talus (Fig. 4). Data on the presence of SP and OT, side of the foot that was evaluated, age, and sex were collected for all subjects.

Statistical Analysis: Statistical analyses were performed using the Statistical Package for the Social Sciences software, version 22 (IBM SPSS Statistics; Turkey). The Shapiro-Wilk test was used to determine the normality of the data. The Chi-square test was used for statistical comparisons, and the results are expressed as mean, standard deviation, and frequency. A p-value less than 0.05 was considered statistically significant.

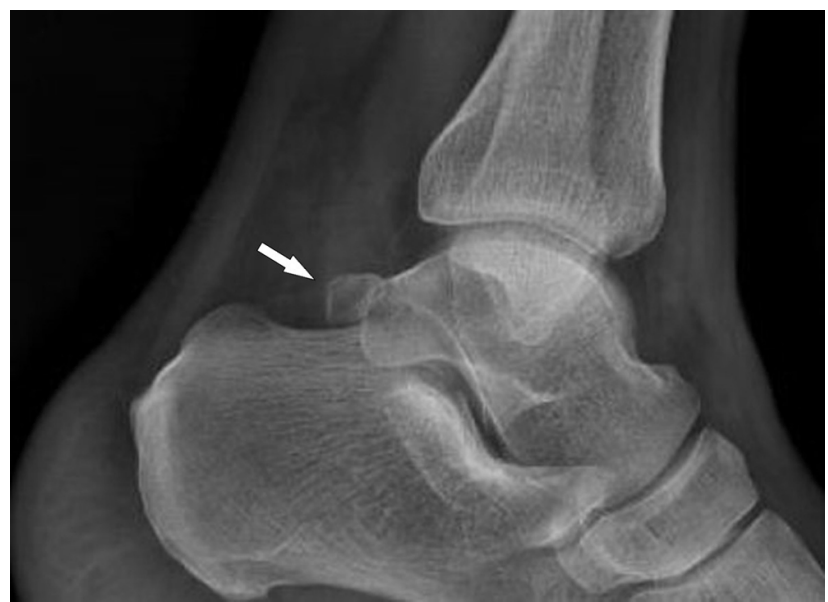

Fig. 3. Lateral radiographs of the ankle showing os trigonum as the non-union of the secondary ossification center of the talus (arrow).

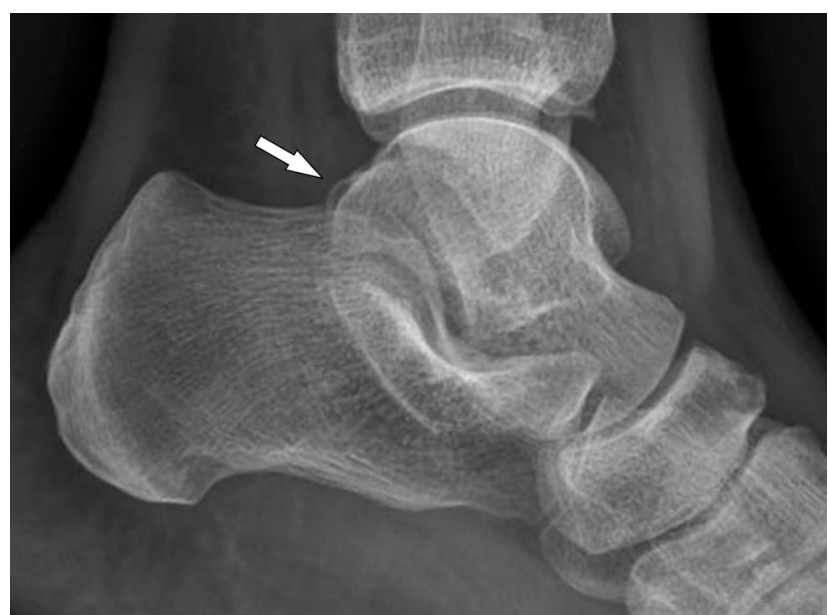

Fig. 4. Lateral radiographs of the ankle showing the posterolateral talar process without prominence. 


\section{RESULTS}

There were 1088 subjects in the study, including 576 $(52.9 \%)$ men and $512(47.1 \%)$ women. The mean age of the subjects was $35.86 \pm 15.79$ years, and the age range was $15-95$ years. The right and left feet were evaluated in 565 $(51.9 \%)$ and $523(48.1 \%)$ patients, respectively.

In our study, the prevalence of SP and OT was 16.7 $\%$ and $9.3 \%$ respectively. The prevalence of SP in men and women was $20.3 \%$ and $12.7 \%$ respectively, showing a significant difference. Further, the prevalence of OT in men and women was $13.7 \%$ and $4.3 \%$ respectively, showing a significant difference (Table I).

The prevalence of SP in the right and left feet was 17 $\%$ and $16.4 \%$ respectively, which was not statistically different. Further, the prevalence of OT in the right and left feet was $9.9 \%$ and $8.6 \%$ respectively, which was also not statistically different (Table II).

Table I. Distribution of prevalence of the os trigonum and Stieda process between sexes.

\begin{tabular}{llcccr}
\hline & & \multicolumn{2}{c}{ Sex } & Total & \\
& & Male & Female & & \\
& $\mathrm{n}(\%)$ & $\mathrm{n}(\%)$ & $\mathrm{n}(\%)$ & \\
\hline Stieda Process & Absent & $459(79.7)$ & $447(87.3)$ & $906(83.3)$ & $0.001^{*}$ \\
& Present & $117(20.3)$ & $65(12.7)$ & $182(16.7)$ & \\
Os Trigonum & Absent & $497(86.3)$ & $490(95.7)$ & $987(90.7)$ & $0.000^{*}$ \\
& Present & $79(13.7)$ & $22(4.3)$ & $101(9.3)$ & \\
\hline
\end{tabular}

Chi-squared Test $* \mathrm{p}<0.05$

Table II. Distribution of prevalence of the os trigonum and Stieda process between body sides

\begin{tabular}{llcccr}
\hline & & Right & Side & Total & \\
& & $\mathrm{n}(\%)$ & $\mathrm{n}(\%)$ & $\mathrm{n}(\%)$ & \\
& & $469(83)$ & $437(83.6)$ & $906(83.3)$ & 0.809 \\
\hline \multirow{2}{*}{ Stieda Process } & Absent & $96(17)$ & $86(16.4)$ & $182(16.7)$ & \\
& Present & $509(90.1)$ & $478(91.4)$ & $987(90.7)$ & 0.458 \\
& Absent & $56(9.9)$ & $45(8.6)$ & $101(9.3)$ & \\
\hline Chi-squared Test & Present & 50.05 & & &
\end{tabular}

\section{DISCUSSION}

PAIS is characterized by posterior ankle pain during plantar flexion. It is caused by excessive repetitive plantar flexion (ballet dancers, gymnasts, and basketball, soccer, and football players) or traumatic events, often in combination with congenital anatomic anomalies such as OT and SP (Niek van Dijk; Coskun et al., 2009; Morelli et al., 2017).

A secondary ossification center in the foot appears at the age of 8-13 years in the posterolateral aspect of the talus and generally fuses with the talus within one year. When it does not fuse with the talus, it is referred to as OT. OT articulates with the lateral tubercle through a fibrocartilaginous synchondrosis located between the ossicle and the talus (Bureau et al.). In a study on the presence of OT on magnetic resonance imaging in cases of impingement, OT was found in $70.1 \%$ of the subjects with PAIS and 1.7 $\%$ of the subjects without PAIS (p < 0.001) (Özer \& Yıldırım,
2019). There is no consensus in the literature on the prevalence of this ossicle, as it varies widely $(2 \%-32.5 \%)$ (Burman \& Lapidus, 1931; Tsuruta et al., 1981; Bureau et al.; Cilli \& Akçaoglu, 2005; Zwiers et al., 2018).

There were no studies showing the prevalence of SP until a study in 2018. Zwiers et al. conducted this study using computed tomography in smaller patient groups with different ethnicities. They reported a higher prevalence of OT $(32.5 \%)$ compared with previous studies. They evaluated the frequency by dividing the posterior talar process into four groups based on the classification by Sarrafian \& Kelikian (2011) and defined types III and IV for an enlarged lateral talar process. They defined SP by evaluating the shape of the lateral tubercle in the axial view, but did not measure the dimensions. In this study, SP was detected in $34.9 \%$ to $36.5 \%$ of the ankles. 
Radiography in the lateral view is ideal to evaluate the bony structures in the posterior region of the ankle (Datir \& Connell, 2010; Nwawka et al., 2013). OT is best visualized on radiographs acquired in the lateral view. A cross-sectional examination is required to evaluate the shape of the posterior talar process. For an objective assessment, we considered measuring the length of the lateral tubercle on lateral radiographs as the distance between the posterior contour of the medial tubercle and posterior contour of the lateral tubercle of the posterior talar process (Fig. 1). A cut-off value for the length of SP has not been defined.

We found two studies in the literature on the prevalence of OT in the Turkish population (Coskun et al.; Uygur et al., 2016). OT was the third most common accessory bone, accounting for $15.4 \%$ of the cases in the study by Uygur et al. and $2.7 \%$ in the study by Coskun et al. In both studies, the presence of OT was detected on radiography, but the results were different. In addition, we found a regional study with fewer subjects reporting a prevalence of $11.9 \%$ for OT (Kir et al., 2011). There have been no studies on the prevalence of SP in the Turkish population.

In our study, the prevalence of OT was higher in men than in women, consistent with the findings reported by Uygur et al. Furthermore, we found that the prevalence of SP was significantly higher in men than in women. In a study by Coskun et al., although the frequency of OT was higher in men than in women, there were no statistically significant differences between the sexes or sides (right and left). In our study, the prevalence of OT and SP was similar on both sides.

OT may be confused with fractures of the lateral process of the talus (Shepherd's fracture). However, fractures are characterized by sharp edges and discontinuity of the cortical lining (Mellado et al., 2003; Lee et al., 2008; Köse, 2012).

This study has several limitations. First, this was a one-dimensional study, as the elongation of the posterolateral process can be well-demonstrated on lateral radiographs but not on axial radiographs. The level of elongation, which is clinically relevant, is unknown. Further, there were too few bilateral cases; thus, statistical data on the possibility of bilateral variations could not be obtained.

In this study, OT and SP were detected in $9.3 \%$ and $16.7 \%$ of the subjects, which means that $26 \%$ of the Turkish population were predisposed to posterior impingement. Osseous impingements can be treated through conservative methods, but may require open or arthroscopic treatment.
In the literature, the importance of early diagnosis and treatment to prevent morbidity has been emphasized (Abramowitz et al., 2003; Yasui et al., 2016; Kudas et al., 2016). Therefore, we recommend radiographic evaluation of these structures, especially in individuals interested in sports, considering its prevalence. Further studies should focus on measuring SP dimensions in large patient groups with and without impingement.

In conclusion, approximately one-fourth of Turkish subjects has SP or OT, which makes them susceptible to PAIS. The prevalence of SP is higher than that of OT, and both are more common in men than in women in the Turkish population. Therefore, clinicians should provide early diagnosis and treatment of SP and OT for ankle health management.

Compliance with Ethical Standards: All procedures performed in studies involving human participants were in accordance with the ethical standards of the Ethics Committee and with the 1964 Helsinki declaration and its later amendments or comparable ethical standards.

CICEK, E. D. \& BANKAOGLU, M. Prevalencia del proceso talar posterior alargado (Proceso de Stieda) detectado por radiografía. Int. J. Morphol., 38(4):894-898, 2020.

RESUMEN: El proceso de Stieda (Stieda process) (SP) y el Os trigonum (OT) son factores de riesgo primarios para el síndrome de pinzamiento del tobillo posterior. El objetivo de este estudio fue determinar la prevalencia del tubérculo lateral alargado del proceso talar posterior (SP) y OT en sujetos turcos mediante radiografías laterales de tobillo. Se evaluaron retrospectivamente 1088 radiografías de tobillo con vista lateral, utilizando un sistema de archivo y comunicación de imágenes en dos centros médicos importantes. Los sujetos con antecedentes de trauma leve a moderado fueron seleccionados en las unidades de urgencia de ambos hospitales de enero a junio de 2019. Se registraron datos sobre la presencia de SP y OT, el lado del pie que se evaluó, el sexo y la edad. La prevalencia de SP y OT fue de $16,7 \%$ y $9,3 \%$, respectivamente, en la población turca. La prevalencia de SP fue significativamente mayor en hombres $(20,3 \%)$ que en mujeres $(12,7 \%)(\mathrm{p}=0,001)$. La prevalencia de OT también fue significativamente mayor en hombres $(13,7 \%)$ que en mujeres $(4,3 \%)(\mathrm{p}=0,000)$. El SP y OT se encontraron en $17 \%$ y $9,9 \%$ de los pies derechos, respectivamente, y $16,4 \%$ y $8,6 \%$ de los pies izquierdos, respectivamente, sin diferencia estadística. Aproximadamente un cuarto de la población turca tenía SP u OT, lo que los hizo susceptibles al síndrome de pinzamiento del tobillo posterior. La prevalencia de SP fue mayor que la de OT, y ambos fueron más comun en hombres que en mujeres.

PALABRAS ClAVE: Proceso Stieda; Os trigonum; Radiografía lateral; Tobillo; Población turca. 


\section{REFERENCES}

Abramowitz, Y.; Wollstein, R.; Barzilay, Y.; London, E.; Matan, Y.; Shabat, S. \& Nyska, M. Outcome of resection of a symptomatic os trigonum. J. Bone Joint Surg. Am., 85(6):1051-7, 2003.

Bureau, N. J.; Cardinal, E.; Hobden, R. \& Aubin, B. Posterior ankle impingement syndrome: MR imaging findings in seven patients. Radiology, 215(2):497-503, 2000.

Burman, M. S. \& Lapidus, P. W. The functional disturbances caused by the inconstant bones and sesamoids of the foot. Arch. Surg., 22(6):93675,1931

Cilli, F. \& Akçaoglu, M. The incidence of accessory bones of the foot and their clinical significance. Acta Orthop. Traumatol. Turc., 39(3):2436, 2005.

Coskun, N.; Yuksel, M.; Cevener, M.; Arican, R. Y.; Ozdemir, H.; Bircan, O.; Sindel, T.; Ilgi, S. \& Sindel, M. Incidence of accessory ossicles and sesamoid bones in the feet: a radiographic study of the Turkish subjects. Surg. Radiol. Anat., 31(1):19-24, 2009.

Datir, A. \& Connell, D. Imaging of impingement lesions in the ankle. Top. Magn. Reson. Imaging, 21(1):15-23, 2010.

Kir, H.; Kandemir, S.; Olgac, M.; Yildirim, O. \& Sen, G. The incidence and distribution of accessory ossicles of the foot. SETB, 45(2):44-7, 2011.

Köse, O. The accessory ossicles of the foot and ankle; a diagnostic pitfall in emergency department in context of foot and ankle trauma. J. Acad. Emerg. Med., 11:106-14, 2012.

Kudas, S.; Dönmez, G.; Isık, Ç.; Çelebi, M.; Çay, N. \& Bozkurt, M. Posterior ankle impingement syndrome in football players: Case series of 26 elite athletes. Acta Orthop. Traumatol. Turc., 50(6):64954,2016

Lee, J. C.; Calder, J. D. \& Healy, J. C. Posterior impingement syndromes of the ankle. Semin. Musculoskelet. Radiol., 12(2):154-69, 2008.

Mellado, J. M.; Ramos, A.; Salvadó, E.; Camins, A.; Danús, M. \& Saurí, A. Accessory ossicles and sesamoid bones of the ankle and foot: imaging findings, clinical significance and differential diagnosis. Eur. Radiol., 13 Suppl. 4:L164-77, 2003.

Morelli, F.; Mazza, D.; Serlorenzi, P.; Guidi, M.; Camerucci, E.; Calderaro, C.; Iorio, R.; Guzzini, M. \& Ferretti, A. Endoscopic excision of symptomatic os trigonum in professional dancers. J. Foot Ankle Surg., 56(1):22-5, 2017

Nault, M. L.; Kocher, M. S. \& Micheli, L. J. Os trigonum syndrome. J. Am. Acad. Orthop. Surg., 22(9):545-53, 2014.

Niek Van Dijk, C. Anterior and posterior ankle impingement. Foot Ankle Clin., 11(3):663-83, 2006.

Nwawka, O. K.; Hayashi, D.; Diaz, L. E.; Goud, A. R.; Arndt, W. F. 3rd; Roemer, F. W.; Malguria, N. \& Guermazi, A. Sesamoids and accessory ossicles of the foot: anatomical variability and related pathology. Insights Imaging, 4(5):581-93, 2013.

Özer, M. \& Yıldırım, A. Evaluation of the prevalence of os trigonum and talus osteochondral lesions in ankle magnetic resonance imaging of patients with ankle impingement syndrome. J. Foot Ankle Surg., 58(2):273-7, 2019

Robinson, P. \& White, L. M. Soft-tissue and osseous impingement syndromes of the ankle: role of imaging in diagnosis and management. Radiographics, 22(6):1457-69, 2002.

Sarrafian, S. K. \& Kelikian, A. S. Osteology. In: Kelikian, A. S. (Ed.). Sarrafian's Anatomy of the Foot and Ankle: Descriptive, Topographic, Functional. $3^{\text {rd }}$ ed. Philadelphia, Lippincott Williams \& Wilkins, 2011.

Stieda, L. Ueber secundäre Fusswurzelknochen. Arch. Physiol. Wissensch. Med., 108-11, 1869.

Tsuruta, T.; Shiokawa, Y.; Kato, A.; Matsumoto, T.; Yamazoe, Y.; Oike, T.; Sugiyama, T. \& Saito, M. Radiological study of the accessory skeletal elements in the foot and ankle (author's transl). Nihon Seikeigeka Gakkai Zasshi, 55(4):357-70, 1981.
Uygur, E.; Aktas, B.; Öz, T. T.; Erinç, S. \& Koç, M. Prevalence of accessory bones of the foot in Turkish patients. J. Academic Research in Medicine (JAREM), 6:147-51, 2016.

Yasui, Y.; Hannon, C. P.; Hurley, E. \& Kennedy, J. G. Posterior ankle impingement syndrome: A systematic four-stage approach. World $J$. Orthop., 7(10):657-63, 2016.

Zwiers, R.; Baltes, T. P. A.; Opdam, K. T. M.; Wiegerinck, J. I. \& van Dijk, C. N. Prevalence of os trigonum on CT imaging. Foot Ankle Int., 39(3):338-42, 2018.

Corresponding author:

(ORCID ID: 0000-0002-0391-3003)

Icerenköy mah Fatih Sultan Mehmet

Training and Research Hospital

Atasehir, 34752

Istanbul

TURKEY

E-mail: eederin@gmail.com

Received: 27-11-2019

Accepted: 27-01-2020 